\title{
Inpatient falls prevention: state-wide survey to identify variability in Western Australian hospitals
}

\author{
AUTHORS \\ CHANTAL FERGUSON BMBS, BMedSci, BSc, MPH, \\ FAFPHM $^{1}$ \\ Perth Business Centre WA 6849 \\ LOUISE MASON RN, BNurs, MNurs ${ }^{1}$ \\ PORTIA HO BPhys ${ }^{1}$ \\ CORRESPONDING AUTHOR \\ LOUISE MASON WA Department of Health, PO Box 8172, Perth Business Centre WA 6849. \\ Email: Louise.Mason@health.wa.gov.au
}

1 Western Australian Department of Health, PO Box 8172,

\section{ABSTRACT}

Objective: A point prevalence survey was conducted across Western Australia to monitor adherence to evidence-based practices to prevent falls in hospitals.

Study design and methods: A state-wide point prevalence survey of patients and their medical records was conducted across 20 hospitals, over 17 days during May 2014. The survey determined rates of: provision of verbal information to patients; completion of a falls risk screening tool and age based cognitive testing. Univariate and multivariate logistic regression was utilised to determine key risks and opportunities to improve.

Results: Information was collected from 2,720 patients. The provision of verbal information to prevent falls, as recalled by patients was $60 \%$ (hospital range 35-88\%). This was significantly higher for patients with a stay of six or more days or involved in rehabilitation care. Perinatal women were three times less likely to be provided with verbal falls prevention information. A falls risk screening tool was completed for $82 \%$ of patients (range $28-98 \%$ ). Perinatal women, and both adult and paediatric patients compared to older adults, were significantly less likely to have a complete falls risk screening tool. Thirty seven percent of patients within the recommended age ranges had cognitive testing (range 0-87\%). Short-term patients and those not involved in rehabilitation, were significantly less likely to have been tested.

Discussion: The survey identified differences in patient care and supporting processes across all hospitals. The results have highlighted areas for improvement.

Conclusion: There were wide variations across all the hospitals in the provision of falls information, completion of falls risk screening tools and cognitive testing. At significant risk of missing out on falls prevention strategies were short stay patients and perinatal women. Five hospitals had significantly low rates of cognitive testing, indicating a hospitalwide issue rather than specific patient cohorts. Subsequently, the importance of ensuring that falls prevention strategies are conducted is vital to reduce preventable inpatient falls in all care settings.

Implications for research, policy and practice:

- This was the first state-wide point prevalence study in WA and it has informed the need for further research into the implication of falls risk inpatients.

- It was found that falls risk assessment was not conducted for each patient who met the screening criteria. A review of the criteria, and practicability to carry out the assessment may need to be further investigated to determine if the practice should be refined. 
What is already known about the topic?

- Falls in hospitals are a frequent and largely considered preventable health concern.

- Falls that occur in hospitals are associated with an increased length of stay and use of health resources.

\section{What this paper adds:}

- This paper offers a comprehensive insight into the variation in hospital falls prevention strategies, from a state-wide perspective. It also identifies perinatal women as a high-risk group who are missing out on falls prevention strategies despite having the potential to fall.

- It also gives an insight to health services that not all at risk patients are being screened and those screened are not screened early in their inpatient stay which can be a risk to both patient and staff.

Keywords: Patient, falls, accidental falls, prevention, surveys, hospitals, risk assessment/methods

\section{INTRODUCTION}

Falls in hospitals are a frequent and largely considered preventable health concern. Falls that occur in hospitals are associated with an increased length of stay and use of health resources. ${ }^{1-3}$ In Australia, in 2015-16, about 34,000 episodes of care reported a fall that occurred in a health service, at a rate of 3.2 per 1,ooo separations. In the same year, Western Australia had falls resulting in patient harm at rates of 5.0 per 1,00o episodes (in public hospitals) and 1.5 (in private hospitals). ${ }^{4}$ As the risk of falls increases with age, appropriate falls prevention strategies will need to be implemented, to prevent inpatient falls within a hospital setting, as Australia's population is ageing.

Systematic reviews have shown that risk factors for falls in hospital patients are multivariate and there is limited evidence to support any one intervention. Therefore, interventions targeting multiple risk factors can reduce falls in hospitals. ${ }^{5,6}$ In Australia, the assessment and management of inpatient falls is governed by evidenced-based guidelines. ${ }^{2,7}$

Western Australia has a population of over 2.5 million people, across 2.6 million $\mathrm{km}^{2}$, and the majority live in metropolitan areas. Rather than relying on voluntary falls incident reporting and sporadic limited audits, this study aimed to obtain state-wide prevalence estimates of falls prevention strategies, to identify hospitals and risk factors that required further improvements.

\section{METHOD}

The study received ethics approval from the Department of Health, Human Research Ethics Committee (\#12/2014).

\section{PARTICIPATION}

Hospitals were included in the falls survey if they had at least 40 acute and/or subacute beds and admitted public patients. Accordingly, 14 metropolitan and six regional hospitals throughout the state were included in the study, conducted over 17 days in May 2014. Participants included multiday- stay public inpatients from acute and subacute wards in the hospital. Exclusions: dialysis patients, mental health wards, newborns, hospital in the home, and day surgery/ procedure patients due to lack of documentation required to participate, or variability in patient behaviour.

\section{AUDIT TOOL AND DATA COLLECTION}

Qualitative and quantitative data were collected by over 400 surveyors who attended educational sessions and passed a competency test. Each audit was conducted by a hospitalbased clinician with an external surveyor.

Survey teams examined medical records for each eligible patient. The survey assessed compliance with the latest guidelines to reduce falls: provision of verbal information to patients; completion of a falls risk screening tool; and agebased cognitive testing (falls prevention strategies).

Univariate and multivariate logistic regression analyses were used to determine if hospitals or significant factors affected the probability of patients receiving falls prevention strategies.

\section{DATA ANALYSIS}

The rates and ranges for each fall prevention strategy performed at each hospital were calculated. Data was supplemented through data linkage to obtain previous admissions and diagnoses, socio-economic status obtained from the Australian Bureau of Statistics and hospital accessibility.

Univariate analysis was used to calculate the association between the patient characteristics (eg. age, gender, rurality, Indigenous status, hospital location) and the probability of receiving a falls prevention strategy. Multiple regression analysis was undertaken for the probability of receiving a test at a participating hospital.

Odds ratios (ORs) were obtained from the models to compare outcomes against the reference hospital (hospital 11 - with the largest group of audited patients). Attributable burden was calculated for an annual basis to estimate the number of patients potentially affected by any significant factors. 


\section{FINDINGS}

\section{PARTICIPANTS}

Information was collected from 2,720 patients. Similar numbers of male and female patients participated.

\section{FALLS INFORMATION PROVIDED TO PATIENTS}

Patients were asked if they had been involved in discussions about ways to prevent falls in hospital. Of the 2,720 patients, 560 patients $(20 \%)$ were unavailable to answer at the time (e.g. cognitive impairment, dementia, on day leave from the hospital) and 30 patients (1.1\%) had no documented response to the question.

Of those able to answer, $60 \%$ of patients (1,276 patients) recalled having received information on falls prevention, ranging from 33-87\% across 20 hospitals (Table 1, Figure 1).

\section{TABLE 1: PERCENTAGE OF PATIENTS WHO WERE PROVIDED WITH VERBAL INFORMATION ON FALLS PREVENTION.}

\begin{tabular}{|l|r|r|}
\hline $\begin{array}{l}\text { Provision of verbal information } \\
\text { on falls prevention }\end{array}$ & Count & Percent \\
\hline No & 854 & 40.1 \\
\hline Yes & 1,276 & 59.9 \\
\hline Total & 2,130 & 100 \\
\hline
\end{tabular}

Patients with a length of stay of six or more days were significantly more likely to have been provided with falls prevention information than patients with a lower length of stay, OR 1.8 (95\% CI: 1.5-2.2). Similarly, patients categorised as having care involving rehabilitation were significantly more likely to have been provided with verbal falls prevention information than those without this care type, $\mathrm{OR}=1.8 \mathrm{a}$

(CI:1.4-2.3). The odds of a patient with a principal diagnosis of single spontaneous delivery (eg. perinatal women) were three times lower than for patients without this diagnosis, OR 0.3 (CI:0.2-0.6), Table 2.

The multivariate logistic model was used to determine if any hospitals were outliers. After adjusting for variations in patient type and complexity, the probability of a patient being provided with verbal information regarding falls prevention was no greater or lower than the odds of a patient in the reference hospital 11 (medium sized metropolitan hospital).

The estimated burden attributable for each significant risk factor was calculated. This calculates the estimated annual change in the number of individuals when the risk factor is absent from the population. For example, the annual number of patients not provided with falls information would be 1,925 perinatal women.

\section{FALLS RISK SCREENING TOOL}

Screening identifies patients at risk of falling or suffering serious harm from falls, and identifies activities to mitigate the risk. Overall the state mean percentage of patients who had been risk assessed for falls with a screening tool was $82 \%$. There were various risk screening tools used across the state (Table 3). Seven hospitals had significantly higher rates of

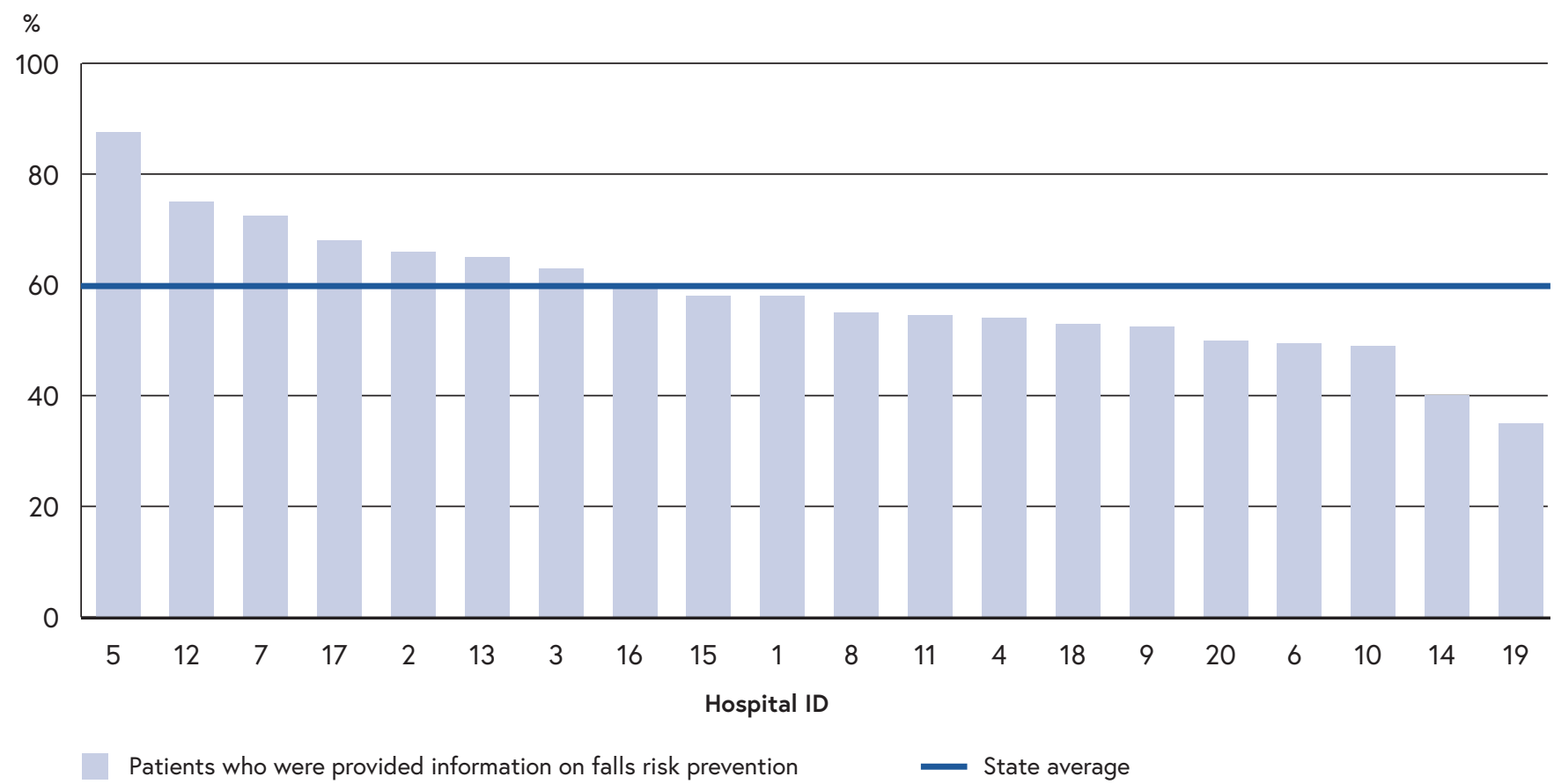

FIGURE 1: PERCENTAGE OF PATIENTS WHO WERE PROVIDED WITH VERBAL INFORMATION ON FALLS PREVENTION BY HOSPITAL 
TABLE 2: ODDS RATIOS OF THE PROBABILITY OF A PATIENT BEING PROVIDED WITH VERBAL INFORMATION ON FALLS PREVENTION

\begin{tabular}{|c|c|c|c|c|c|}
\hline Patient Characteristic & Reference Group & $\begin{array}{l}\text { Adjusted OR } \\
\text { (lower and upper } \\
\text { confidence } \\
\text { intervals) }\end{array}$ & $\begin{array}{l}\text { Change in the } \\
\text { number of patients } \\
\text { with the outcome }\end{array}$ & $\begin{array}{l}\text { Annual change in the } \\
\text { number of patients } \\
\text { with the outcome }\end{array}$ & $\begin{array}{l}\text { Annual change as a } \\
\text { percentage of the } \\
\text { estimated annual } \\
\text { number of patients } \\
\text { with the risk factor }\end{array}$ \\
\hline $\begin{array}{l}\text { Length of Stay } \\
6+\text { days }\end{array}$ & $\begin{array}{l}\text { Length of Stay } \\
0-5 \text { days }\end{array}$ & $\begin{array}{l}1.862 \\
(1.542,2.249)\end{array}$ & $\begin{array}{l}-117 \\
(-153,-83)\end{array}$ & $\begin{array}{l}-1,842 \\
(-2,397,-1306)\end{array}$ & $\begin{array}{l}-14 \\
(-18,-10)\end{array}$ \\
\hline $\begin{array}{l}\text { Past principal diagnosis } \\
\text { of rehabilitation }\end{array}$ & - & $\begin{array}{l}1.756 \\
(1.358,2.271)\end{array}$ & $\begin{array}{l}-43 \\
(-61,-23)\end{array}$ & $\begin{array}{l}-924 \\
(-1,309,-492)\end{array}$ & $\begin{array}{l}-12 \\
(-17,-6)\end{array}$ \\
\hline $\begin{array}{l}\text { Current principal } \\
\text { diagnosis of single } \\
\text { spontaneous delivery }\end{array}$ & - & $\begin{array}{l}0.326 \\
(0.184,0.575)\end{array}$ & $\begin{array}{l}16 \\
(8,23)\end{array}$ & $\begin{array}{l}1,925 \\
(990,2,741)\end{array}$ & $\begin{array}{l}26 \\
(13,37)\end{array}$ \\
\hline
\end{tabular}

using falls screening tools than the mean and five hospitals were significantly lower (Figure 2).

Once adjusted for variations in patient type and complexity, the following were significantly less likely to have been risk assessed with a falls risk screening tool: adults compared to older adults, paediatrics compared to older adults, and perinatal women.

Based on the risk assessment scores, 1,161 (56.7\%) patients were classified as at risk of falling. 47 (2.3\%) patients had missing information.
TABLE 3: FALLS RISK SCREENING TOOL USED

\begin{tabular}{|l|r|r|}
\hline Falls risk screening tool used & Count & Percent \\
\hline $\begin{array}{l}\text { Falls Risk Assessment and Management } \\
\text { (FRAMP) }\end{array}$ & 74 & 2.72 \\
\hline Falls Risk Management Tool (FRMT) & 1,653 & 60.77 \\
\hline Hospital-specific tool A & 154 & 5.66 \\
\hline Hospital-specific tool B & 85 & 3.13 \\
\hline Hospital-specific tool C & 79 & 2.90 \\
\hline WACHS Falls Risk Management Tool & 166 & 6.10 \\
\hline No tool present & 495 & 18.20 \\
\hline Missing & 14 & 0.51 \\
\hline Total & 2,720 & 100 \\
\hline
\end{tabular}

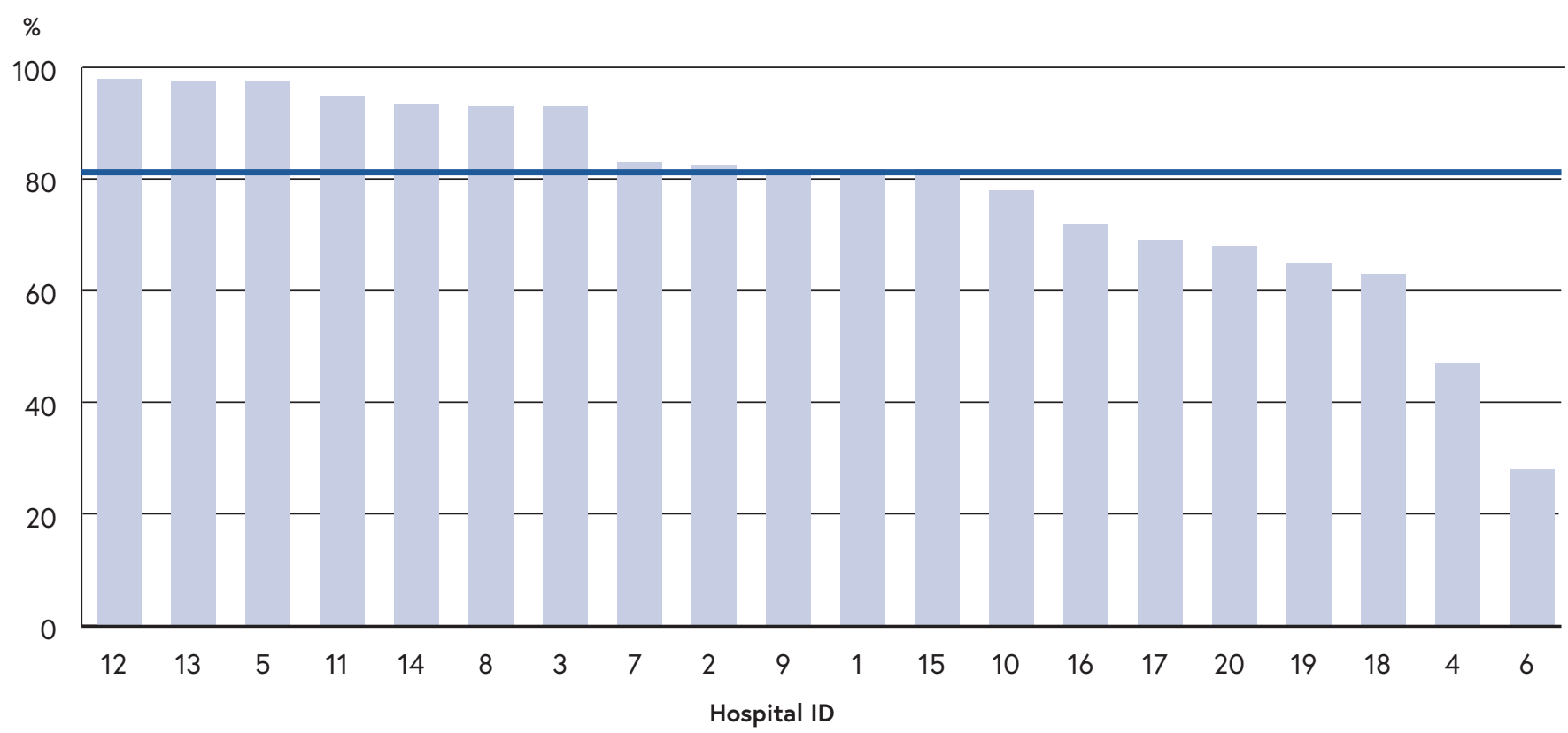

Patients who had a fall risk screening tool State average

FIGURE 2: PERCENTAGE OF PATIENTS IN EACH HOSPITAL WHO HAD BEEN RISK ASSESSED FOR FALLS WITH A SCREENING TOOL. 


\section{COGNITIVE IMPAIRMENT SCREENING}

Completion of cognitive impairment screening was captured in the survey. The cohort included all non-Aboriginal patients aged 65 years or older (1,383 patients) and all Aboriginal patients aged 45 years and older (61 patients). Five patients did not have documented responses to the questions, therefore the final cohort consisted of 1,439 patients. There was a range of cognitive tools used across the state. Table 4 shows the distribution of the tools used. Five hundred and twenty-nine patients had documented evidence of cognitive testing.

The state mean percentage of patients with documented cognitive testing was $36.7 \%$ across all hospitals. There were three hospitals with no documented evidence of cognitive testing (Figure 3).

\section{TABLE 4: COGNITIVE TESTING TOOL USED}

\begin{tabular}{|l|r|r|}
\hline Cognitive testing tools used & Count & Percent \\
\hline Abbreviated Mental Test 4 & 169 & 11.70 \\
\hline Abbreviated Mental Test Score & 119 & 8.24 \\
\hline Mini Mental State Examination & 118 & 8.17 \\
\hline $\begin{array}{l}\text { Rowland Universal Dementia } \\
\text { Assessment Scale }\end{array}$ & 8 & 0.55 \\
\hline Other cognitive test & 115 & 7.96 \\
\hline No evidence of testing & 910 & 63.02 \\
\hline Total & 1,439 & 100 \\
\hline
\end{tabular}

$\%$

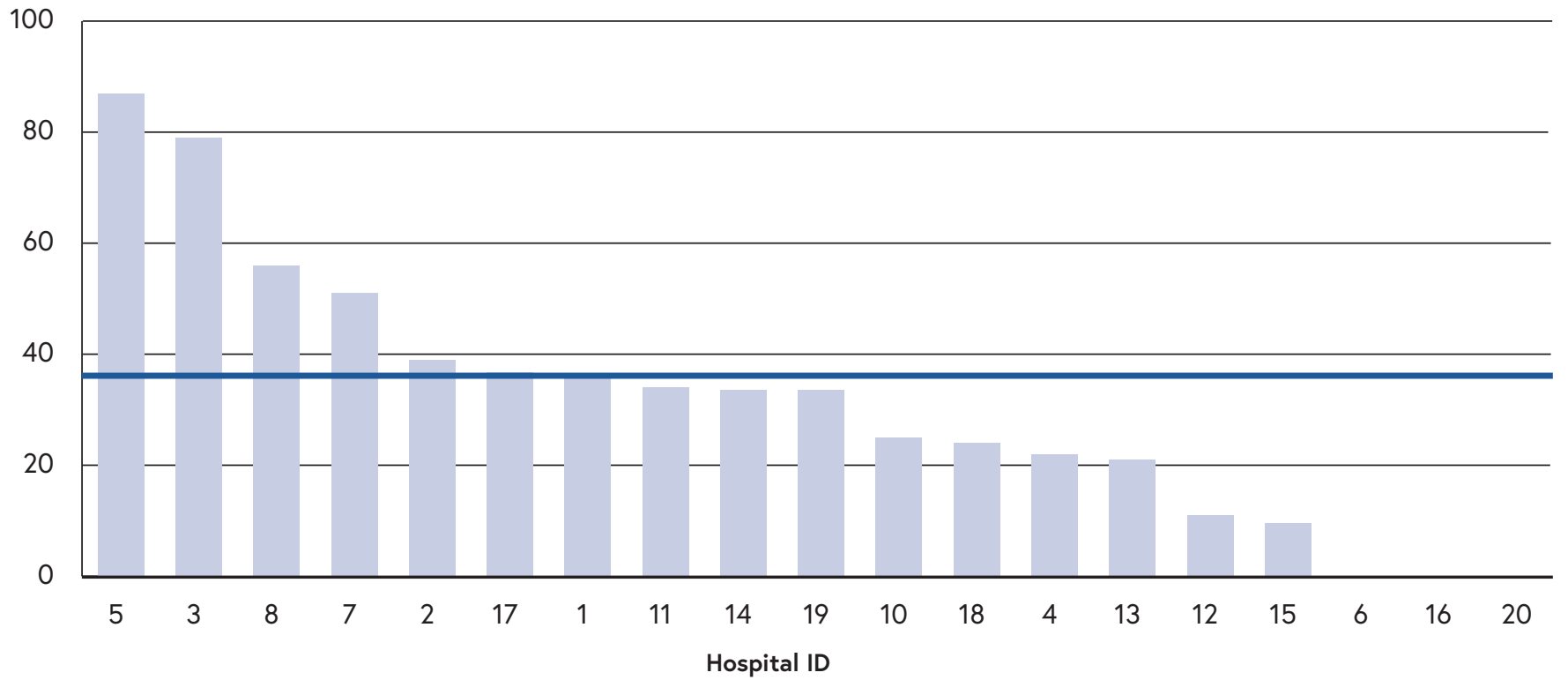

Patients who showed evidence of cognitive testing
To determine if any hospitals were outliers, using multivariate logistic regression, short-term patients and patients not involved in rehabilitation procedures were significantly less likely to have been provided with cognitive testing. After adjusting for these factors, five hospitals had significantly lower rates of testing compared to the reference hospital 11, and three hospitals performed significantly more cognitive testing.

\section{DISCUSSION}

The survey identified differences in patient care and supporting processes across all hospitals. The results have highlighted areas for improvement.

Falls prevention information was provided to many patients (60\%), although wide variations existed across different hospitals (35-88\%). This is consistent with other studies, such as Stoeckle et al. and Stephenson et al., where the rates were reported as low as 30\%. 8,9

Falls information provision was higher in some hospitals; although not significant once patient type and complexity were accounted for. Short-term patients, patients not involved in rehabilitation care and perinatal women were identified as significantly missing out on this information. Multivariable logistic regression identified that targeted interventions for these groups (over 20,0oo patients annually) would increase the provision of falls information rates, rather than targeting specific hospitals. These patient groups may be perceived to have a higher probability of being more mobile and agile and therefore less likely to
Hospital ID 
require the information, even though they have the potential to fall. Long stay patients were identified as having a higher risk of falls consistent with the literature..$^{10-12}$

Hospitals should also consider multiple and less resource intensive strategies to educate patients and carers, such as providing information on hospital TV channels and handouts such as Patient First resources, ${ }^{13}$ rather than only providing verbal information. Almis et al. and Schoberer et al. reinforce the need to involve carers and families in falls prevention strategies and in the development of educational materials. ${ }^{10,14}$ For older adults, a study suggested that falls prevention education should focus more on the positive benefits of improving balance, to improve compliance and prevent unintentionally patronising patients. ${ }^{15}$

Compliance with using a falls risk screening tool was high in this audit overall (82\%, range $28-98 \%$ ). This is consistent with other studies. ${ }^{8,9}$ Adult, paediatric and birthing patients were less likely to have had a falls risk assessment tool compared to older adults. While there is the perception that older adults are more likely to fall, younger patients are also at risk and some epidemiology studies of falls in hospitals have found the highest rates of falls were not in the older adult population. ${ }^{11,16,17}$ Table 3 identifies the many different screening tools used. In order to facilitate the incorporation of best practice guidelines, following the survey a standardised Falls Risk Assessment and Management Plan (FRAMP) was developed for use in the general adult population. ${ }^{5}$ The FRAMP centralises and simplifies core requirements into one form and guides staff through the essential screening, assessment and management processes. ${ }^{5}$

Birthing patients have a short-term increased risk of falling and generic falls risk tools do not always capture them. ${ }^{11}$ Falls prevention strategies need to address the unique characteristics of the different patient groups and should consider using more appropriate risk assessment tools, such as the Post Epidural Fall Risk Assessment Score (PEFRAS). ${ }^{11}$

The state mean percentage of patients with documented evidence of cognitive testing was $37 \%$ across all hospitals. This is consistent with other studies. ${ }^{18}$ Five hospitals had significantly low rates of cognitive testing, indicating a hospital-wide issue to be addressed rather than specific patient cohorts.

The literature cites that cognitive impairment increases the frequency of patient falls. Incorporating early delirium recognition and management in a falls prevention program in the acute care setting is highly recommended. ${ }^{19-23}$

Since the survey was conducted, hospitals received individualised results. Local strategies have since been introduced including greater awareness campaigns, development of patient information resources, and a statewide falls network for sharing of information and education resources. Targeted information to increase cognitive testing has also been promoted alongside national standards focusing on falls and cognitive impairment. ${ }^{24}$
The survey represents evidence that was available on the day of the survey. Limitations of the study include: data was collected from a large number of surveyors recruited across WA Health with varying levels of clinical and audit experience. To mitigate this, a number of data verification steps were applied both on the day and during the data entry, including entries being double checked.

The number of patients included from some of the participating hospitals was statistically small and patient groups differed substantially on a number of important characteristics including age, presenting conditions and severity of illness across hospitals. Subsequently, comparison of results at the individual hospital level was generally not appropriate but has been included in some areas as a guide to the differences in results between hospitals.

\section{CONCLUSION}

The overall prevalence of falls prevention advice and risk assessment were within the expected range compared with national estimates. The analysis of compliance with the use of a falls risk assessment tool and the provision of falls prevention information to patients has revealed several areas of clinical practice which if targeted could result in decreased falls.

Amongst hospitals there were wide variations in the provision of falls information, falls risk screening tools and cognitive testing. Patients in rehabilitation care, older adults, and long stay patients were significantly more likely to have falls prevention strategies provided. At significant risk of missing out on falls prevention strategies were short stay patients and perinatal women, which may benefit from further research. Five hospitals had significantly low rates of cognitive testing, indicating a hospital-wide issue to be addressed rather than specific patient cohorts.

\section{Acknowledgements:}

- Patients and staff at participating hospitals across Western Australia and the Western Australia Department of Health

- Annie Chacha-Gan (Project Manager, Department of Health)

- Dr Amanda Ling (Executive Lead, Joondalup Health Campus)

- Collaborative for Healthcare Analysis and Statistical Modelling (CHASM), University of Western Australia.

- Survey questions available on request.

Ethics approval: The study attained ethical approval from the Department of Health Human Research Ethics Committee (\#12/2014).

Funding: The authors received no financial support for the research, authorship, and/or publication of this article.

Competing interests: The authors declare no competing interests. 


\section{REFERENCES}

1 Morello RT, Barker AL, Watts JJ, Haines T, Zavarsek SS, Hill KD, et al. The extra resource burden of in-hospital falls: a cost of falls study. Med J Aust. 2015; 203(9): 367e1-e8. Available from: https://doi.org/10.5694/mja15.00296

2 Australian Commission on Safety and Quality in Health Care (ACSQHC). Preventing falls and harm from falls - fact sheet. Australian Commission on Safety and Quality in Health Care. Sydney. 2010. [cited 2019 May 10] Available from: https://www. safetyandquality.gov.au/wp-content/uploads/2012/01/NSQHSStandards-Fact-Sheet-Standard-10.pdf

3 Hill KD, Vu M, Walsh W. Falls in the acute hospital setting -impact on resource utilization. Aust Health Rev. 2007; 31(3): 471-77

4 Australian Institute of Health and Welfare (AlHW). Australia's health. Australian Institute of Health and Welfare. Canberra, ACT. 2018. [cited 2019 May 1] Available from: https://www. aihw.gov.au/reports/australias-health/australias-health-2018/ contents/table-of-contents

5 Western Australian Department of Health. Development of falls risk assessment and management plan. Western Australian Department of Health. Perth, WA. 2015.[cited 2019 Jun 1] Available from: https://ww2.health.wa.gov.au/ /media/Files/ Corporate/general\%20documents/falls/PDF/Dev-of-FRAMP.pdf

6 Butcher, L. The no-fall zone. Hosp Health Netw. 2013. 87(6): 26-30.

7 Australian Commission on Safety and Quality in Health Care (ACSQHC). Preventing falls and harm from falls in older people: best practice guidelines for Australian hospitals Australian Commission on Safety and Quality in Health Care. Sydney. 2009. [cited 2019 May 7] Available from: https:// www.safetyandquality.gov.au/wp-content/uploads/2009/01/ Guidelines-HOSP.pdf

8 Stoeckle A, Iseler JI, Havey R, Aebersold C. Catching quality before it falls: preventing falls and injuries in the adult emergency department. J Emerg Nurs. 2019; 45(3): 257-64 Available from: https://doi.org/10.1016/j.jen.2018.08.001

9 Stephenson M, McArthur A, Giles K, Lockwood C, Aromataris E, Pearson A. Prevention of falls in acute hospital settings: a multisite audit and best practice implementation project. Int J Qual Health Care. 2016; 28(1): 92-98.

10 Almis $\mathrm{H}$, Bucak $\mathrm{H}$, Konca C, Turgut M. Risk factors related to caregivers in hospitalized children's falls. J Pediatr Nurs. 2017; 32: 3-7.

11 Lockwood S, Anderson K. Postpartum safety: a patient-centered approach to fall prevention. MCN Am J Matern Child Nurs. 2013; 38(1): 15-18.

12 Simpson KR. Patient falls in the perinatal setting. MCN Am J Matern Child Nurs. 2010; 35(6): 364.

13 Western Australian Department of Health. Patient first resources. Western Australian Department of Health. 2020 [cited 2020 May 20] Available from: https://healthywa.wa.gov. au/Articles/F I/Going-to-hospital

14 Schoberer D, Breimaier HE, Mandl M, Halfens RJG, Lohrmann C. Involving the consumers: an exploration of users' and caregivers' needs and expectations on a fall prevention brochure: a qualitative study. Geriatr Nurs. 2016; 37(3): 207-14.

15 Yardley L, Donovan-Hall M, Francis K, Todd C. Older people's views of advice about falls prevention: a qualitative study. Health Educ Res. 2006; 21(4): 508-17.
16 Anderson DC, Postler TS, and Dam TT. Epidemiology of hospital system patient falls: a retrospective analysis. Am J Med Qual. 2016; 31(5): 423-28.

17 Dionyssiotis Y. Analyzing the problem of falls among older people. Int J Gen Med. 2012; 5: 805-13.

18 Blackwood JA. Screening for Cognitive Impairment as a Part of Falls Risk Assessment in Physical Therapist Practice. J Geriatr Phy Ther. 2017; 40(4): 197-203.

19 Sillner AY, Holle CH, Rudolph JL. The overlap between falls and delirium in hospitalized older adults: a systematic review. Clin Geriatr Med. 2019; 35(2): 221-36.

20 Ambrose AF, Paul G, Hausdorff JM. Risk factors for falls among older adults: a review of the literature. Maturitas. 2013; 75(1) $51-61$.

21 National Institute for Health and Care Excellence. Clinical Guideline CG161: Falls in older people: assessing risk and prevention. 2013. [cited 202028 Feb] Available from https://www.nice.org.uk/guidance/cg161/chapter/1Recommendations\#preventing-falls-in-older-people-during-ahospital-stay-2

22 Muir SW, Gopaul K, Montero Odasso MM. The role of cognitive impairment in fall risk among older adults: a systematic review and meta-analysis. Age Ageing. 2012; 41(3): 299-308.

23 Lakatos BE, Capasso V, Mitchell MT, Kilroy SM, LussierCushing $M$, et al. Falls in the general hospital: association with delirium, advanced age, and specific surgical procedures. Psychosomatics. 2009; 50(3): 218-26.

24 Australian Commission on Safety and Quality in Health Care (ACSQHC). National safety and quality health service standards user guide for health service organisations providing care for patients with cognitive impairment or at risk of delirium. 2019. [cited 2019 June 7] Available from: https://www. safetyandquality.gov.au/our-work/cognitive-impairment/betterway-to-care/ 